\title{
Booking system, video conferencing (VC) solution and online forms for improving child psychiatric services in Pohjois-Savo region
}

\author{
Kirsi Bykachev ${ }^{1}$, M.Sc. (Econ.), B.Sc. (Soc.), Outi Turunen ${ }^{1}$, M.Sc. (Health Sciences), Marjorita Sormunen ${ }^{1}$, Ph.D., \\ Jussi Karppi ${ }^{2,3}$, M.D., Kirsti Kumpulainen ${ }^{2,3}$, M.D., Ph.D., Hannele Turunen ${ }^{1,4}$, Ph.D. \\ ${ }^{1}$ Department of Nursing Science, University of Eastern Finland, Kuopio, Finland; ${ }^{2}$ School of Medicine, University \\ of Eastern Finland, Kuopio, Finland; ${ }^{3}$ Department of Child Psychiatry, Kuopio University Hospital, Kuopio, Finland; \\ ${ }^{4}$ Kuopio University Hospital, Kuopio, Finland
}

Kirsi Bykachev, M.Sc. (Econ.), B.Sc. (Soc.), Project Manager, University of Eastern Finland, Department of Nursing Science, Kuopio, FINLAND. Email: kirsi.bykachev@uef.fi

\begin{abstract}
Purpose Early detection and timely treatment of child psychiatric problems require multi-professional collaboration and interaction between primary and specialized health care. The "eHealth Services for Child and Adolescent Psychiatry (eCAP), 2015-2018" project aims at improving child psychiatric services in peripheral areas by developing eHealth tools facilitating better cooperation between professionals working with children with mental health problems.
\end{abstract}

Methods The online booking system allows the primary healthcare professionals in Pohjois-Savo region to book a video conference (VC) with experts in child psychiatry for consultation, supervision or follow-up of care. Background information gathered from the parents, teacher and the child by online forms helps the consult to prepare for the meeting, which can be carried out on computer, laptop, table or smartphone. The developed services will be evaluated based on the log data and user experiences from the pilot phase.

Results The services will improve the quality, availability and cost-effectiveness of child psychiatric outpatient services in the region. Increased multi-professional collaboration among professionals will support preventive work, early identification and treatment in natural developmental environments of children. The travel needs for families are expected to decrease.

Conclusions eHealth can help to meet the global challenge of providing sufficient, timely child psychiatric services in remote, sparsely populated areas with limited resources, but information security and compatibility of different technical applications require innovative solutions. Furthermore, the people-related factors are crucial in introducing a sustainable change: the users must understand the benefits and receive training to adopt the new tools and routines for their work.

Keywords: child psychiatry, telemedicine, referral and consultation 